\title{
The Effect of Ultrasonic Energy on Joint Characterization in Ultrasonic Spot Welding Multilayer Tabs Used in Lithium-ion Battery Manufacturing
}

\author{
Z.N. $\mathrm{Ma}^{1}$ and Y.S. Zhang ${ }^{1, *}$ \\ ${ }^{1}$ Shanghai Key Laboratory of Digital Manufacture for Thin-Walled Structures, Shanghai Jiao Tong University, Shanghai 200240, P.R. \\ China
}

\begin{abstract}
Lithium-ion battery for electric vehicles contains a large number of battery tabs with multiple and thin sheets. Dissimilar metals are often used for different electrodes, for example, the copper and nickel are often used for negative electrode and the aluminum is often used for positive electrode. Meanwhile the thickness of metal sheets are various at different locations. Ultrasonic spot welding is very capable of welding similar and dissimilar combinations. However, there are less heat generation and plastic deformation in the bottom interfaces where ultrasonic energy is difficult to reach. This will result in the unbonded region occurrence caused by ultrasonic energy attenuation.

In this work, experimental investigation was conducted to identify the effect of ultrasonic energy on joint characterization in ultrasonic welding multiple tabs by comparing the plastic deformation in different layers and various joint interfaces. Two sonotrodes with different knurl size were used to produce the welding energy for the tabs joining. Samples were cross-sectioned along vibration direction to obtain hardness profiles and metallographic maps. The hardness profile can be used to identify the changes of grain morphology. Hardness and grain size changes in different layers were also studied to reflect how ultrasonic energy decrease from top to bottom in battery tabs. Thereby, the relationship between material attributes and ultrasonic energy loss was established based on the experimental results.
\end{abstract}

\section{Introduction}

Ultrasonic welding is a solid-state bonding technology which is capable of joining complex structures such as multilayer, dissimilar materials and thin foils [1]. It is also a low cost, low energy consumption, and environment friendly technology $[2,3,4]$.

The electric vehicle battery pack contains a large number of lithium battery cells. Cells are connected in series or parallel by their battery tabs where ultrasonic welding technology is widely used. However, it is difficult to joint too many layers of tabs at the same time. Usually, three or more layers of battery tabs are jointed together with an electric collector. And the electric collector will connect many groups of battery tabs together.

In the ultrasonic welding process of multilayer structures, the ultrasonic energy transfers from the sonotrode to the bottom metal foil successively. This process is accompanied with energy loss which may lead into inconsistent welding quality of different interfaces [5]. Moreover, sonotrode transfer pressure and vibration to the top foil directly and to other foils indirectly. This can lead into inconsistent force, plastic deformation and heat generation in different layers. To ensure the bottom metal sheets bonding well, the input energy is usually bigger than two-sheets welding. When input energy raises, the bottom interface weld quality will raise while the top foils face the risk of severe deformation or crack $[6,7]$. So it is valuable to study the different features in different layers and interfaces. Lee et al. [8] studied various features to descript ultrasonic welding quality including post weld thickness, weld nugget size, thermal-mechanical affected zone size and hardness in cross section. Wu et al. [9] studied the microstructure and failure of three layers of battery tabs and one layer of bus bar. Nickle-plated copper was used in this study, and the copper would expose after peel test which could be considered as the bonding area. A dark field microscopy technique was used accompanied with photo processing technique to measure the size of bonding area. Lee et al. [10] used high-speed images to analysis the movement of each layer in lithium-ion battery tabs bonding process during which three layers of battery tabs and one layer of bus bar were jointed together. The camera with high capture frequency was set towards the lateral side of four layers of material to capture the displacement of each layer during the welding process. Lee et al. [11] created a 2D finite element model to simulate temperature and structure field of a four-sheets structure where sonotrodes with different geometry were used. Also different welding parameter was selected to

Corresponding author: zhangyansong@sjtu.edu.cn 
compare the different results. According to the simulation results, stress and strain distributed in the top sheet was much bigger than other layers. Kang et al. [12] studied the energy loss in ultrasonic welding process. One-dimensional continuous vibration models were established in this study. They come up with methods to reduce the vibration energy loss by designing the weld tools and samples.

As many studies pointed out, plastic deformation in the interface is a major bonding mechanism of ultrasonic welding. However, when it comes to multilayer structure, the different degree of plastic deformation in different layers can result in different welding quality of each interface. In this work, features of different layers were studied in order to find out the difference in attributes of each layers, especially the plastic deformation during ultrasonic welding process. Experiments with different welding time were carried out. In each time point, the cross sections of samples were observed for the post weld thickness, grain deformation and hardness [13]. Also, the real-time vertical displacement of sonotrode was recorded to reflect the real-time plastic deformation of copper sheets.

\section{Experimental}

Sheets of two different thickness were used: $0.2 \mathrm{~mm}$ nickel-plated copper sheets and $0.8 \mathrm{~mm}$ copper sheets without plating. The base material was selected as T2 pure copper (Ingredient content $(\%)$ : $\mathrm{Cu} 99.9$, Sn 0.002, Zn 0.005 , Pb 0.005, Ni 0.005, Fe 0.005, Sb 0.002, S 0.005, As 0.002, Bi 0.001, O 0.06). The nickel coating was approximately $2 \mu \mathrm{m}$ which was usd to protect the copper sheets from corrosion. Sample sheets were all cut into $20 \mathrm{~mm} \times 50 \mathrm{~mm}$ pieces. The welder used in this study is Tech-sonic Viper-20. Every sample was formed by three layers of $0.2 \mathrm{~mm} \mathrm{Ni}$-plated copper sheets and one layer of $0.8 \mathrm{~mm}$ copper sheet (Fig. 1). All samples were welded at the center of the sheet.

The ultrasonic welding parameters was selected as follow: $3.5 \mathrm{bar}$ of welding pressure, $23 \mu \mathrm{m}$ of vibration amplitude, $0.2 \mathrm{~s} \sim 0.8 \mathrm{~s}$ (interval $0.2 \mathrm{~s}$ ) of welding time.
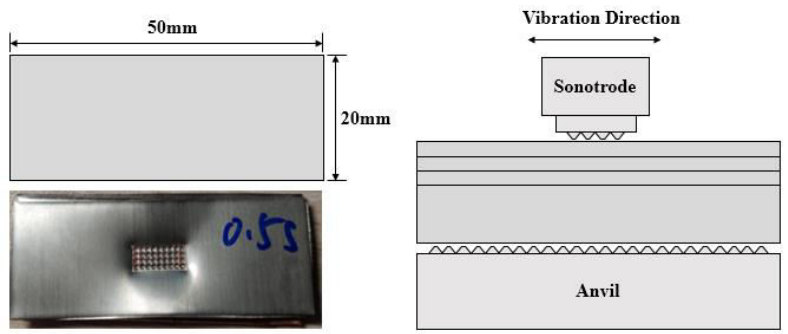

Fig 1. Configuration of samples and welding process

Two different sonotrodes with pyramid teeth were used in this research. The shape of two kinds of pyramid teeth are showed in Figure 2. The sonotrode I was equipped with smaller teeth contains 36 teeth which arrayed in a $4 \times 9$ matrix while the sonotrode with bigger ones contains 18 teeth which arrayed in a $3 \times 6$ matrix.
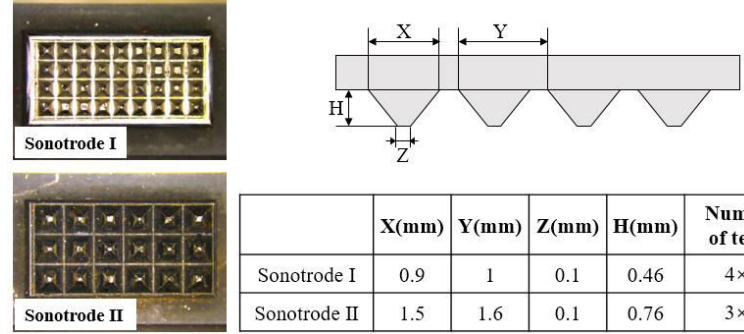

\begin{tabular}{|c|c|c|c|c|c|}
\hline & $\mathbf{X}(\mathbf{m m})$ & $\mathbf{Y}(\mathbf{m m})$ & $\mathbf{Z}(\mathbf{m m})$ & $\mathbf{H}(\mathbf{m m})$ & $\begin{array}{c}\text { Number } \\
\text { of teeth }\end{array}$ \\
\hline Sonotrode I & 0.9 & 1 & 0.1 & 0.46 & $4 \times 9$ \\
\hline Sonotrode II & 1.5 & 1.6 & 0.1 & 0.76 & $3 \times 6$ \\
\hline
\end{tabular}

Fig 2. Shape and size of two kinds of sonotrodes

The displacement of ultrasonic weld sonotrode during ultrasonic welding process was studied in this research. A WenglorMEL M70LL displacement sensor was used and set as Figure 3 to obtain the real-time vertical displacement of sonotrode during ultrasonic welding process. The range of displacement sensor was $2 \mathrm{~mm}$ and the sampling frequency was set as $2 \mathrm{kHz}$. An oscilloscope produced by Virtins Technology was used to transfer signals from the sensor to the computer for further analysis.

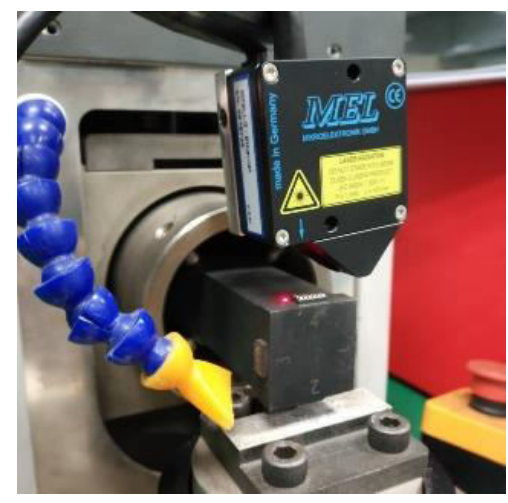

Fig 3. Position of displacement sensor

In order to measure the postweld thickness of each layer, samples were cross cut along the sonotrode vibration direction. Then the small pieces of samples were insert into epoxy resin for better polishing and observation. The observation position is the cross section under middle sonotrode teeth (Fig 4). Considering the obvious material wearing during polishing process, the initial cutting position should be away from the final position. And the polishing process should be acted carefully to make sure that the final position is accurate.

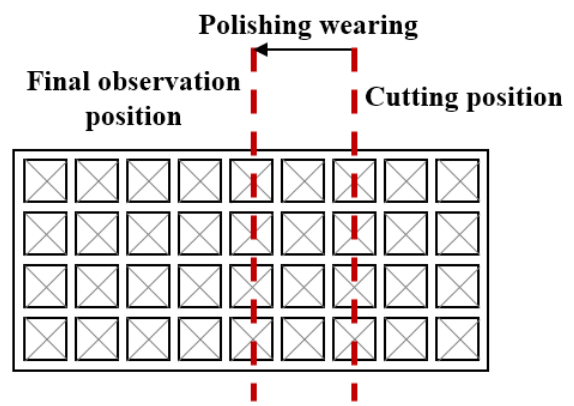

Fig 4. Cutting position and observation position 
Corrosion test is carried out to study the change in grain boundaries. The corrosive was a mixture of $5 \mathrm{~g}$ $\mathrm{Fe}(\mathrm{NO}) 3,10 \mathrm{ml}$ ethanol and $50 \mathrm{ml}$ distilled water. This corrosive was dropped on the well-polished cross section and stayed for 5 seconds, then cleaned by water and ethanol. Samples after corrosion were observed by an optical microscope.

Hardness test were carried out to analysis the effect on materials' hardness of ultrasonic welding process. Test points were selected from the outmost teeth to outside of the cross section (Fig 5). A Vickers hardness tester was used under the pressure of $25 \mathrm{gf}$ and hold of $10 \mathrm{~s}$. The test points were selected horizontally equally spaced.

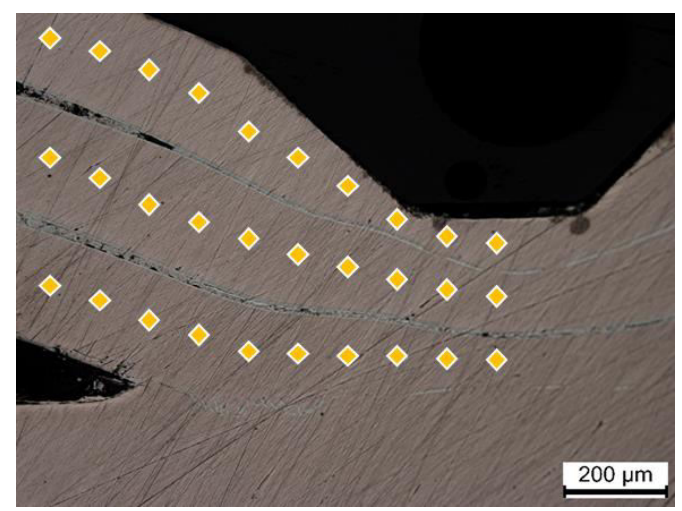

Fig 5. Hardness test location

\section{Results}

This section shows the direct results of experiment mentioned above. Vertical displacement of sonotrode, plastic deformation of copper sheets, grain deformation and hardness profile in cross section are displayed separately and the mechanism of results are discussed briefly.

\subsection{Vertical Displacement of Sonotrode}

The vertical displacement of sonotrode from vibrating beginning to stop was intercepted and studies. The displacement data from weld samples of different welding time $(0.3 \mathrm{~s}, 0.5 \mathrm{~s}$ and $0.7 \mathrm{~s})$ were put in a line chart together (Fig. 6). It can be seen that the sonotrode declines during the weld process all the time, but the slope of displacement curve changes obviously at some certain points. At the beginning of welding process, the vertical displacement of sonotrode increase slowly while from $0.1 \mathrm{~s}$ to $0.2 \mathrm{~s}$ the displacement increased rapidly. When the weld time come to $0.2 \mathrm{~s}$, the slope of displacement curve decreased. Whereas, after $0.5 \mathrm{~s}$ the sonotrode declined rapidly again. Repetitive experiments were conducted to prove this law was steady.

The whole welding process can be divided into four stages according to the slope. In stage I (before $0.1 \mathrm{~s}$ ), the sonotrode declined slowly because the copper sheet still stayed in the original state with high stiffness. As the welding process continue, copper sheets were under the acoustic softening effect and become easier to be deformed. In stage II $(0.1 \mathrm{~s}$ to $0.2 \mathrm{~s})$, obvious plastic deformation occurred in copper sheets, so the displacement of sonotrode increased rapidly. However, the serious plastic deformation was associated with work hardening. In stage III $(0.2 \mathrm{~s}$ to $0.5 \mathrm{~s})$, plastic deformation is difficult to continue in the top copper sheet which lead into a decrease in curve slope. In stage IV (after $0.5 \mathrm{~s}$ ), the first layer foil was penetrated by the pyramid teeth. The second layer of copper sheet was easy to be deformed because of less work hardening occurred. So the slope increased again.

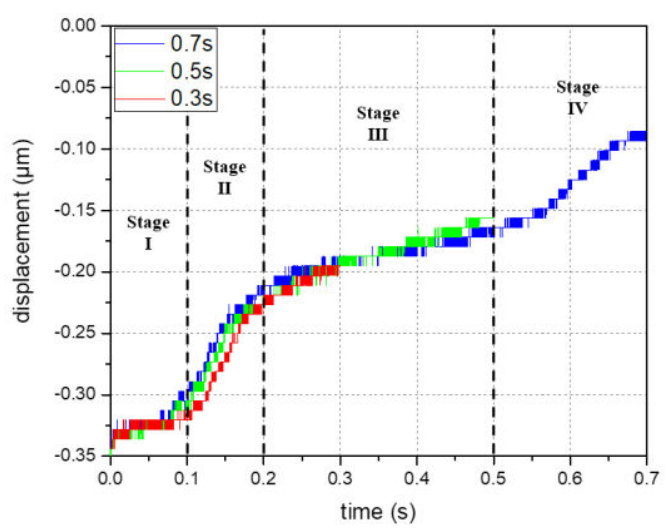

Fig 6. Vertical displacement of sonotrode during the ultrasonic vibration process

\subsection{Post Weld Thickness}

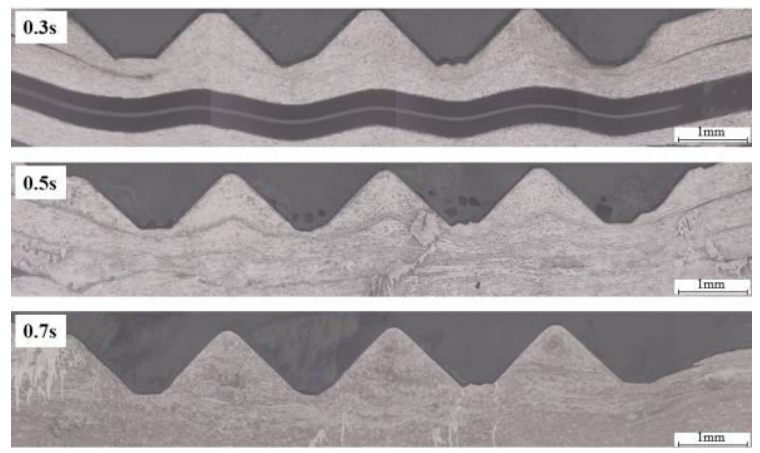

(a)
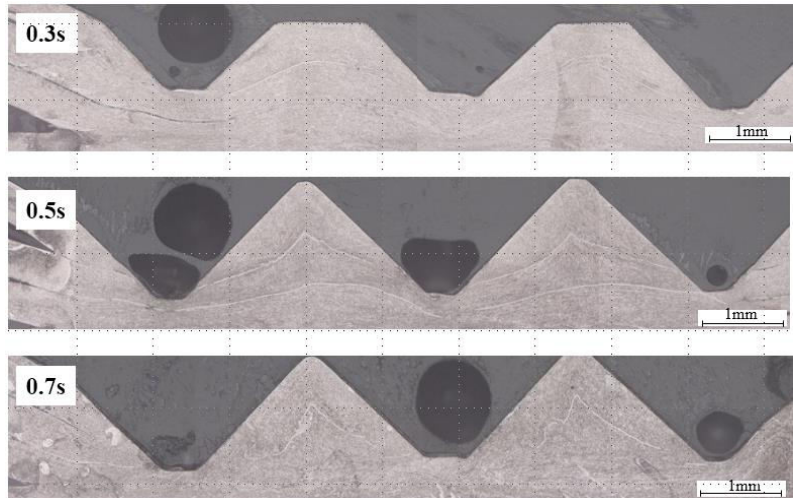

(b)

Fig 7. (a) cross section of samples made by sonotrode I (b)cross section of samples made by sonotrode II 
Post weld thickness of different weld times and sonotrodes were compared. The metallographic maps of cross sections can be seen in Figure 7. Compared with sonotrode I, sonotrode II could result in bigger plastic deformation in copper sheets because of its higher sonotrode teeth which can lead into more stress concentration at the area under sonotrode teeth. When the weld time was $0.3 \mathrm{~s}$, the interface between second sheet and third sheet was separated in the sample produced by sonotrode I, while the sample produced by sonotrode II showed well joint in this location. In the sample produced by sonotrode I under welding time of $0.5 \mathrm{~s}$, the post weld thickness of top sheet decrease to a low level. And when weld time was over $0.5 \mathrm{~s}$, the top sheet could be penetrated by the sonotrode teeth. Whereas, when weld time was $0.3 \mathrm{~s}$, the sample produced by sonotrode II showed an obvious plastic deformation in top sheet and the top sheet could be penetrated by the sonotrode when weld time was over $0.3 \mathrm{~s}$.

\subsection{Grain deformation}

The area near to the sonotrode exist extensive grain elongation because of the high pressure and highfrequency ultrasonic vibration of sonotrode [5]. This type of deformation distributed wildly in the area contact with the sonotrode or anvil (Fig 8 (a) (b)). However, as the welding time increasing, the elongated grains disappeared (Fig 8 (c) (d)). This can be the result of recrystallization[8]. In ultrasonic welding process, a large amount of heat would generate from the interfaces because of high-frequency friction. The heat would cause a rapidly temperature raising up to approximately half of copper's melt temperature. Recrystallization was accompanied by the reduction in the hardness and an increase in the ductility. As the recrystallization occurred, copper sheets' deformation become easier.

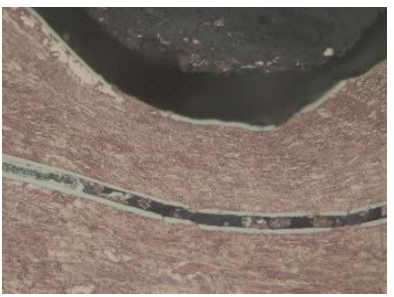

(a)

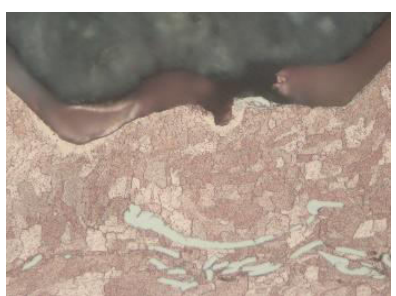

(c)

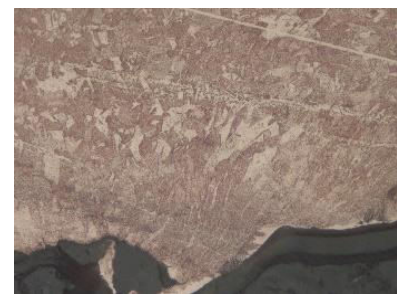

(b)

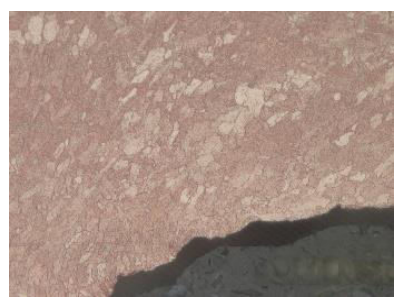

(d)
Fig 8. Grain morphology in the cross section (a) area contact with sonotrode $(0.2 \mathrm{~s}$ welding time) (b) area contact with anvil (0.2s welding time) (a) area contact with sonotrode $(0.8 \mathrm{~s}$ welding time) (a) area contact with anvil ( $0.8 \mathrm{~s}$ welding time)

\subsection{Hardness profiles}

The hardness of area from the outmost teeth to the outside area of cross section was measured. In Figure 9, $\mathrm{Y}$-axis represents for Vickers hardness value and $\mathrm{X}$-axis represents for the horizontal distance from middle of the outmost teeth in cross section. There was an increase of hardness under the teeth because of the effect of work hardening. As the distance from the outmost teeth increase, the effect of work hardening become weak. When the distance was over $0.4 \mathrm{~mm}$, the hardness was below the base material's. This is a result of heat generated in the welding process. In the ultrasonic welding process, a large amount of heat would generate because of the high-frequency friction and the local temperature would raise to $300^{\circ} \mathrm{C}$ or more [14]. After the end of welding process, the heat would dissipate to the sonotrode, the anvil and air. This process was familiar with the annealing process which could soften the material [15].

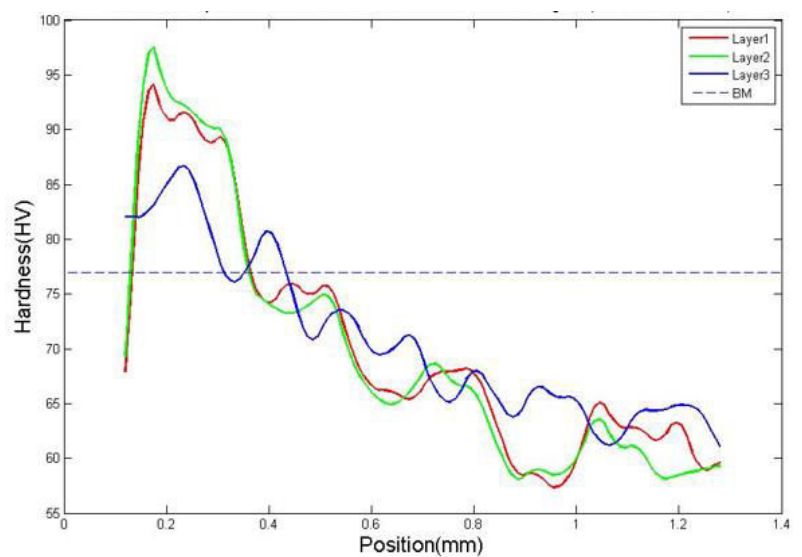

(a)

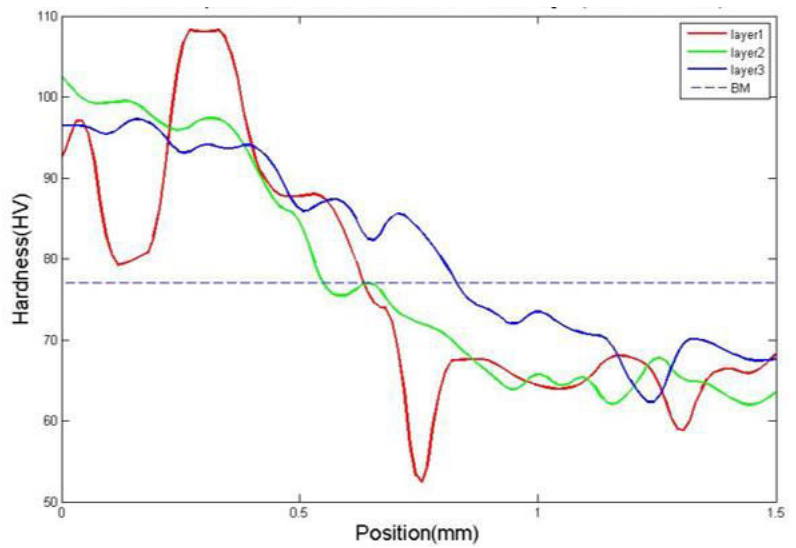

(b)

Fig 9. Hardness profile of weld zone in each layer under $0.3 \mathrm{~s}$ weld time (a) samples by sonotrode I (b) samples by sonotrode II

\section{References}

1. Lee S.S., Kim T.H., Hu S.J., Cai W.W. and Abell J. A., "Joining technologies for automotive lithiumion battery manufacturing: a review," ASME Conf. Proc., Vol. 1, pp. 541-549, Oct. 2010. 
2. Macwan A., Kumar A. and Chen D.L. "Ultrasonic spot welded 6111-T4 aluminum alloy to galvanized high-strength low-alloy steel: microstructure and mechanical properties.", Mater Design, vol. 113, pp. 284-296, Oct. 2017.

3. Raj N.M., Kumaraswamidhas L.A., Nalajam P.K. and Vendan S.A., "Studies on Electro Mechanical Aspects in Ultrasonically Welded Al/Cu Joints", Trans Indian Inst Met, PP. 1-10, May. 2017.

4. Patel V.K., Bhole S.D. and Chen, D. L., "Microstructure and mechanical properties of dissimilar welded $\mathrm{Mg}$-Al joints by ultrasonic spot welding technique." Sci Technol Weld Joi, vol. 17(3), pp. 202-206, 2012.

5. Bakavos, D., and Prangnell, P. B., 2010, "Mechanisms of Joint and Microstructure Formation in High Power Ultrasonic Spot Welding 6111 Aluminium Automotive Sheet", Mater. Sci. Eng., A, vol. 527(23), pp. 6320-6334.2010

6. Fujii H.T., Endo H., Sato Y.S. and Kokawa H., "Interfacial microstructure evolution and weld formation during ultrasonic welding of $\mathrm{Al}$ alloy to Cu", Mate Charact, vol. 139, pp. 233-240, 2018.

7. Shen N., Samanta A., ding H. and Cai W.W., "Simulating microstructure evolution of ultrasonic welding of battery tabs", 44th Proceedings of the North American Manufacturing, vol. 5, pp. 399416, 2016

8. Lee S.S., Kim T.H., Hu S.J., Cai W.W., Abell J.A. and $\mathrm{Li}$ J.J., "Characterization of joint quality in ultrasonic welding of battery tabs", J Manuf Sci E, vol. 135, pp. 021004-1-13, Apr. 2013.

9. Wu X., Liu T. and Cai W., "Microstructure welding mechanism and failure of $\mathrm{Al} / \mathrm{Cu}$ ultrasonic welds", J Manuf Proc, vol. 20, pp. 515-524, 2015.

10. Lee S.S., Kim T.H., Hu S.J., Cai W.W. and Abell J.A., "Analysis of weld formation in multilayer ultrasonic metal welding using high-speed images", J Manuf Sci E, vol. 137, pp. 031016-1-8, June. 2015.

11. Lee D. and Cai W., "The effect of horn knurl geometry on battery tab ultrasonic welding quality: 2D finite element simulations", J Manuf Proc, vol. 28, pp. 428-441, 2017.

12. Kang B.S., Cai W. and Tan C.A., "Vibrational energy loss analysis in battery tab ultrasonic welding", J Manuf Proc, vol. 16, pp. 218-232, 2014.

13. Hetrick, E., Baer, J., Zhu, W., Reatherford, L., Grima, A., Scholl, D., Wilkosz, D., Fatima, S., and Ward, S., 2009, "Ultrasonic Metal Welding Process Robustness in Aluminum Automotive Body Construction Applications," Weld. J., 88(7), pp. 149S-158S.

14. Zhao J.Z., Li H., Choi H., Cai W., Abell J.A. and Li X.C., "Insertable thin film thermocouples for in situ transient temperature monitoring in ultrasonic metal welding of battery tabs", J Manuf Proc, vol. 15, pp. 136-140, 2013.

15. Zhang C.Q., Robson J.D., Ciuca O. and Prangnell P.B., "Microstructural characterization and mechanical properties of high power ultrasonic spot welded aluminum alloy AA6111-TiAl6V4 dissimilar joints", Mater Charact, vol. 97, pp. 8391, Sep. 2014. 